approach to pain relief is advisable, on the basis that it is better to be in pain than to be killed by the analgesic.

Sixteen years have passed since it was suggested that individual variation in analgesic requirements might be met more adequately by allowing patients to decide when pain relief was required, and then letting them give themselves drugs intravenously. ${ }^{3+}$ Apparatus was developed with sensitive controls to enable the clinician to prescribe the incremental and the total doses, the minimum interval between each dose, and the speed of injection. ${ }^{5}$ Routes other than intravenous have now been used successfully including the intramuscular, ${ }^{6}$ sublingual, ${ }^{7}$ and epidural. ${ }^{8}$ On demand systems have been used mainly for relief of postoperative and obstetric pain, but they have also been evaluated in the treatment of coronary pain ${ }^{9}$ and that of terminal disease. ${ }^{8}$

The first meeting on self administered pain relief was held in London recently by the European Academy of Anaesthesiology and was preceded by a workshop. ${ }^{8}$ Agreement was reached on terminology: patient controlled analgesia (PCA), alternative terms being self administered analgesia and on demand analgesia; increment (the incremental dose); lockout time (the minimum interval before another increment is allowed). The advantages of giving a dose tailored to the need of each patient are obvious, for biological variation in response is known to occur ${ }^{5}$ : in one study in which patients used the apparatus to administer analgesia after cholycystectomy total doses in the first 24 hours varied sixfold to tenfold but the mean dose was reassuringly close to that expected from extensive experience with conventional intramuscular regimens (for example, pethidine 600 $\mathrm{mg}$ in 24 hours). ${ }^{6}$ Relief of pain was judged to be good, and most patients liked to be able to regulate their own treatment. $^{8}$ It was agreed, however, that no entirely satisfactory comparison had been made with optimum current practice. That was partly because of the difficulty of defining optimum, and partly because even a randomised study, particularly if double blind, would influence the current practice being examined. A so called optimum conventional prescription might include a dedicated nurse ready to inject an intravenous increment as soon as the patient made a request; if so, then patient controlled analgesia could be no more effective, although it might be less expensive. On the other hand (and more likely), "prn" is usually interpreted as a dose administered when the nurse has time to ask the patient and then decides that another dose is safe and necessary. In these circumstances patient controlled analgesia should result in improved pain reliefand does. ${ }^{10}$

The workshop heard that over 3000 patients had been treated by patient controlled analgesia and there have been no deaths. ${ }^{8}$ Theoretically, the technique should be safer than other regimens as pain is barely (or just) suppressed by the patient but can still act as a stimulus to respiration. Indeed, continuous 24 hour postoperative respiratory monitoring in 30 patients did not show apnoeic periods, ${ }^{8}$ unlike recordings following a continuous infusion regimen." A good start, therefore, has been made in establishing the effectiveness and safety of patient controlled analgesia, and more clinicians may now be encouraged to try this method of pain relief. Manufacturers have enough confidence in the prospects to have developed five apparatuses with different features. Nevertheless, before patient controlled analgesia is widely adopted for routine use-that is, without additional clinical or nursing supervision-it must be shown to be at least as safe as current practice, and further carefully controlled studies are needed. When the results of these studies are available "prn" may become widely replaced by patient controlled analgesia-to the advantage of many patients who now suffer avoidable pain.

M Rosen

Consultant Anaesthetist,

University Hospital of Wales,

Cardiff CF4 4XW

1 Cronin M, Redfern PA. Utting JE. Pswchometry and postoperative complaints in surgical patients. Br J Anaesth 1973;45:879-86.

Holdcroft A, Morgan $\mathrm{M}$. An assessment of the analgesic effect in labour of pethidine and fifty per cent nitrous oxide in oxygen (Entonox. Fournal of Obstetrics and Gynaecology of the British Commonwealth 1974;88:603-7.

3 Sechzer PA. Objective measurement of pain. Anesthesiology 1968;29:209-10.

4 Keeri-Szanto M. Apparatus for demand analgesia. Can Anaesth Soc $\mathcal{f} 1971 ; 18: 581-2$.

Evans JM, Rosen M, MCCarthy J, Hogg MIJ. Patient-controlled intravenous narcotic. Lancet

1976;i:426.
6 Harmer M, Slattery PJ, Rosen M, Vickers MD. Intramuscular on-demand analgesia doubleblind controlled trial of pethidine, buprenorphine, morphine and meptazinol. Br Med $\mathcal{F} 1983$ 286:680-2

Shah MV, Jones DI, Rosen M. Postoperative patient-demand analgesia with buprenorphine comparison between sublingual and intramuscular administration. (Submitted for publication.

Rosen M, Harmer M, Vickers MD, eds. Patient-controlled analgesia? Report on
Castle, fune 5-6, 1984 . European Academy of Anaesthesiology. (In press.)

Elringham RJ, Jones MBS, Burlingham AN, Smith GB. Patient-controlled analgesia following myocardial infarction. Anaesthesia-Points West 1983;16:142.

myocardial infarction. Anaesthesta-Points West 1983;16:142.
10 Slattery PJ, Harmer M, Rosen M, Vickers MD. An open comparison between routine and selfadministered postoperative pain relief. Ann $R$ Coll Surg Engl 1965;1:18-9.

11 Catling JA, Pinto DM, Jordan C, Jones JG. Respiratory effects of analgesia after cholecystectomy: comparison of continuous and intermittent papaveretum. Br Med $\mathcal{J}$ 1980;281:478-80.

\section{Population growth and politics}

The integrity of policy makers in a topic as sensitive and central as human reproduction is a virtue, but the fine line that separates conviction from absolutism remains important. In 1949 Chairman Mao said, "The absurd theory that increases in food cannot catch up with increases in population ... has not only been refuted by Marxists in theory, but has also been overthrown in practice in the postrevolutionary Soviet Union." Eight years later he was saying that "Population [growth] must be controlled." Today, China is in a demographic prison. If $70 \%$ of couples have only one child the population will still increase by 200 million-only slightly less than the current United States population-in the next generation. Mao changed course too late. Women who are pressured into aborting a second pregnancy in the 1980s are the daughters of women who did not have access to realistic family planning choices in the 1960s. The lesson of family planning history is not to let grand theories lose touch with family needs.

The United Nation's international conference held in July in Mexico City was the mirror image of a similar meeting which took place in Bucharest a decade earlier. The 1974 conference was characterised by a division between the developed and developing countries. At that time the developed, led by the United States, were seen by India and many Marxist and Latin American countries as pushing too hard for a demographic solution to the world's economic problems. By contrast, the Indian delegation said that development was the best contraceptive-but by 1976 India was dealing with the disaster of forced vasectomies. The Chinese kept a low profile but within a few years had launched their one child policy. Bucharest confused the world; in retrospect, it may even have set back rational development.

The Mexico City conference put family planning back on the world's agenda. The conference's decisions received overwhelming approval from commentators around the 
world. With a single exception, the developed and developing countries spoke with one voice, endorsing family planning as an integral part of development, acknowledging its contribution to the health of women and children, welcoming the decline in the birth rate which has occurred in many countries in the past 10 years, but never pretending that population change by itself would solve the world's many social and economic problems.

The world's journalists and broadcasters had no doubt that $\mathrm{Mr}$ James Buckley and the United States delegation gathered in Mexico were at odds with the other countries. This belief contributed greatly to the worldwide attention the conference attracted; it probably helped to unify the policies established by all the other nations; and it certainly played a part in the success of the conference. Unlike the Bucharest meeting, the gathering in Mexico City may be judged to have carried the global family movement forward.

The United States came into conflict with the other participants by repeating its policy of denying funds to any agency that "promotes" abortion. During the conference the United States Agency for International Development accepted "concrete assurances" from the United Nations Fund for Population Activities that it does not support abortion or coercive family planning programmes and announced the immediate release of $\$ 19$ million; $\$ 11$ million of projected aid to the International Planned Parenthood Federation, however, remains held back. As a federation of independent associations, the International Planned Parenthood Federation has always encompassed a variety of views on abortion and cannot dictate policy to individual members.

Ever since Bucharest the consensus has been that family planning is needed to supplement the effect of economic development in reducing population growth. Mawai Kabaki, vice president of Kenya, told the meeting in Mexico that the world "cannot wait for the crisis of overpopulation to right itself through economic development." The United States delegation argued that the shoe belonged on the other foot. Citing Hong Kong and South Korea, with their scarce natural resources, as examples Buckley claimed that one of the main forces in their swift progress had been "reliance on the creativity of private individuals working within a free economy." By contrast, he said, a tightly controlled, centrally planned economy tended to "inhibit individual initiative and sometimes crippled the ability of men and women to work toward a better future." In such places, he concluded, "one of the consequences of lagging development was the disruption of the natural mechanism for slowing population growth."

The third plank of the United States platform received the least publicity but remains the most important: a sound reaffirmation of support for voluntary family planning programmes. The United States promised to go above the current $\$ 240$ million earmarked to population and family planning in 1985.
In 1976 the world population was 3.99 billion; currently it stands at 4.76 billion. In the past 10 years the growth in global population has fallen from $2.03 \%$ to $1.67 \%$ per annum; but as the total population has grown the absolute increment has also increased and is over 80 million in the current year. The yearly increases will rise still further before the end of the century. By the year 2000 there will be 1.6 billion women of childbearing age, with 1.3 billion of these living in developing countries. Unless there is a massive increase in family planning efforts, hundreds of millions of these couples will be without access to family planning choices.

Though the goals of the 1974 World Plan of Action from Bucharest have been partially met in fertility regulation, declines in mortality have been disappointing. In Mexico City the Save the Children Fund, Unicef, and the World Health Organisation all drew attention to the need to sustain traditional patterns of breast feeding, to encourage the use of oral rehydration therapy, and to maintain optimum patterns of birth spacing through contraceptive choices in order to reduce infant mortality further.

In summary the world has arrived at a consensus about the right of couples and individuals to decide the number and spacing of their children and the United States, along with other developed nations, has reaffirmed its commitment to economic aid to overseas family planning. Perhaps we cannot and should not ask for more. Inevitably national and religious differences in attitude will persist. The Turkish delegation pointed out that the Holy Koran places a "divine responsibility" on parents to provide for their children. Bishop John Schotte, leader of the Holy See delegation, supported natural family planning but condemned abortion, sterilisation, and artificial methods of contraception. Some government delegations, such as Sweden, explicitly supported all methods, including legal abortion.

If the use of contraceptives world wide could be doubled in the next 10 years-and that is an achievable goal-it would bring the projected world population in AD 2050 down from $12 \cdot 0$ billion to $8 \cdot 4$ billion. Expanding voluntary family planning today will help prevent Mexico, Nigeria, the Philippines, Egypt, and other nations arriving in the Chinese impasse of no choice tomorrow. Family planning programmes may then continue to be, in President Reagan's words, "truly voluntary, cognisant of the rights and responsibilities of individuals and families and respectful of religion and cultural values." Hesitation in following up on the Mexico City conference with vigour and commitment could hazard the precious freedom of our children to determine when and how many babies to have in the world we bequeath them.

President,

Malcolm PotTs

Family Health International,

NC 27709,

USA 